\title{
Leptomeningeal metastases: a RANO proposal for
} response criteria

\author{
Marc Chamberlain, Larry Junck, Dieta Brandsma, Riccardo Soffietti, Roberta Rudà, \\ Jeffrey Raizer, Willem Boogerd, Sophie Taillibert, Morris D. Groves, Emilie Le Rhun, \\ Julie Walker, Martin van den Bent, Patrick Y. Wen, and Kurt A. Jaeckle.
}

\begin{abstract}
Department of Neurology, Fred Hutchinson Cancer Research Center, University of Washington, Seattle, Washington, USA (M.C.); Department of Neurology, University of Michigan, Ann Arbor, Michigan, USA (L.J.); Department of Neuro-Oncology, Netherlands Cancer Institute, Antoni van Leeuwenhoek Hospital, Amsterdam, Netherlands (D.B., W.B.); Department of Neuro-Oncology, University Hospital, Torino, Italy (R.S., R.R.); Department of Neurology, Robert H. Lurie Comprehensive Cancer Center, Northwestern University, Chicago, Illinois, USA (J.R.); Departments of Neuro-Oncology Marazin and Radiation Oncology, Pitie-Salpetrieree Hospital and University Pierre et Marie Curie, Paris VI, Paris, France (S. T.); Austin Brain Tumor Center, Texas Oncology/US Oncology Research, Austin, Texas, USA (M.D.G.); Department of Neuro-Oncology, University Hospital, Department of Neurology, Oscar Lambret Center, Lille, France (E.L.R.); Department of Neuro-Oncology, The University of Texas M.D. Anderson Cancer Center, Houston, Texas, USA (J.W.); Department of Neuro-oncology, Erasmus MC-Daniel den Hoed Cancer Center, Rotterdam, Netherlands (M. v. d. B.); Center for Neuro-Oncology, Dana-Farber/Brigham and Women's Cancer Center, Boston, Massachusetts, USA (P.Y.W.); Departments of Neurology and Oncology, Mayo Clinic Florida, Jacksonville, Florida, USA (K.A.J.)
\end{abstract}

Corresponding Author: Marc C. Chamberlain, MD, University of Washington, Department of Neurology and Neurological Surgery, Fred Hutchinson Research Cancer Center, Seattle Cancer Care Alliance, 825 Eastlake Ave., PO Box 19023, MS G4940, Seattle, WA 98109 (marcchamberlain@gmail.com).

\begin{abstract}
Leptomeningeal metastases (LM) currently lack standardization with respect to response assessment. A Response Assessment in Neuro-Oncology (RANO) working group with expertise in LM developed a consensus proposal for evaluating patients treated for this disease. Three basic elements in assessing response in LM are proposed: a standardized neurological examination, cerebral spinal fluid (CSF) cytology or flow cytometry, and radiographic evaluation. The group recommends that all patients enrolling in clinical trials undergo CSF analysis (cytology in all cancers; flow cytometry in hematologic cancers), complete contrast-enhanced neuraxis MRI, and in instances of planned intra-CSF therapy, radioisotope CSF flow studies. In conjunction with the RANO Neurological Assessment working group, a standardized instrument was created for assessing the neurological exam in patients with LM. Considering that most lesions in LM are nonmeasurable and that assessment of neuroimaging in LM is subjective, neuroimaging is graded as stable, progressive, or improved using a novel radiological LM response scorecard. Radiographic disease progression in isolation (ie, negative CSF cytology/flow cytometry and stable neurological assessment) would be defined as LM disease progression. The RANO LM working group has proposed a method of response evaluation for patients with LM that will require further testing, validation, and likely refinement with use.
\end{abstract}

\section{Key words:}

CSF cytology/flow cytometry | leptomeningeal metastasis | neurological examination | neuraxis MRI.

In a previous article, the authors critically reanalyzed randomized controlled trials (RCT) conducted in leptomeningeal metastases (LM) as well as discussed controversies in the treatment of LM. ${ }^{1}$ The purpose of the current article is to propose new response criteria for LM as part of a Response Assessment in Neuro-Oncology (RANO) working group 
initiative. The goal of the proposed response criteria is to standardize assessment of treatment of patients with LM in clinical trials, which would be of practical use outside of clinical trials. Three elements of treatment response in LM are universally recognized: the neurological examination, the cerebral spinal fluid (CSF) cytology or flow cytometry (FC) evaluation for the presence or absence of circulating tumor cells, and CNS imaging. Consequently, the RANO LM working group recommends that all patients enrolling in LM clinical trials undergo a complete standardized neurological examination (Table 1), CSF analysis (including cytology in all cancers and FC in hematologic cancers), complete contrast-enhanced neuraxis (brain and spine) $\mathrm{MRI}$, and radioisotope CSF flow studies (only in patients treated with intra-CSF therapy) at prespecified times. The majority of RCT in LM patients have utilized a combination of neurological examination and CSF cytology to determine response to treatment. ${ }^{2-8}$ However, no standardized assessment has been used consistently in these studies. Although radiographic assessments were often used in the above-mentioned RCT, radiographic response or impact on treatment varied or was not clearly defined. Currently, there is no well-defined effect of corticosteroids with respect to signs or symptoms of LM or evidence of diminution in LM-related MRI contrast enhancement in patients with nonhematologic cancers. Consequently, steroid dose is not considered in the proposed response criteria for solid tumor-related LM. Steroids are, however, recognized to be oncolytic in hematologic cancers, and consequently steroid dose is considered in the proposed response criteria for LM due to hematologic cancers. It is recognized that corticosteroids have utility in patients with brain metastases as well as in patients with intra-CSF treatment-related neurotoxicity-for example, treatmentrelated chemical meningitis.

\section{Neurological Assessment}

The RANO LM working group in conjunction with the RANO Neurological Assessment working group has created an instrument for assessing the neurological exam in patients with LM that will likely standardize response definitions in forthcoming LM trials and permit crosscomparison among trials (Table 1). ${ }^{9}$ This instrument will require prospective validation, is considered a work in progress, and likely will require future revisions as additional knowledge and use are gained. The domains selected in the standardized neurological examination reflect primary sites of disease involvement by LM. Additionally the neurological examination was designed to be simple so as to allow non-neurologists, including oncologists, nurse practitioners, and physician assistants, to use it. Progressive disease in LM based on neurological assessment is defined by a change of 2 or more levels in a given domain (eg, gait) or alternatively by a change to level 3 (or level 2 in domains defined by only 3 levels) in any one domain (Table 1). It is acknowledged that attribution of disease progression can be challenging, since change in neurological function may also occur secondary to coexistent brain metastases, systemic disease progression, concurrent medications (including corticosteroids), or treatment-related toxicity. As the majority of neurological deficits due to LM are fixed and irreversible, it is anticipated that best response to treatment usually will be stabilization of neurological function (ie, stable disease as assessed by neurological examination; Table 2). Transient neurological symptoms or deficits often are treatment related and do not represent progression of LM. Neurological examination is recommended to be determined at baseline in the conduct of a clinical trial and at the prespecified evaluation timepoints, preferably by a single examiner to minimize exam variability.

There is increasing evidence that patient-reported outcomes (PROs) and performance status are prognostic indicators of both progression-free survival and overall survival in various cancers, including primary and metastatic brain tumors. ${ }^{10-13}$ Cognitive and motor functioning as well as general symptoms are of prognostic importance in brain tumor patients. ${ }^{10,14}$ Though there are no published reports of $\mathrm{PROs}$ as an indicator of treatment response in LM patients, intuitively it is likely that quality-of-life measures, along with neurological examination, may also provide valuable insight into overall treatment response and tolerance. Suggested but not included as response criteria for LM is incorporation of a symptom inventory such as the MD Anderson Cancer Center Symptom Inventory Brain Tumor Module (MDASI-BT) or the MD Anderson Cancer Center Symptom Inventory Spine Tumor Module (MDASI-SP), as currently there is no method to capture LM-relevant symptoms such as headache, nausea/vomiting, or seizures. Obtaining baseline PRO measures utilizing tools such as the MDASI-BT or MDASI-SP helps define symptoms such as pain or incontinence, and a quality-oflife measure such as the Functional Assessment of Cancer Therapy-Brain as an adjunct to the neurological examination likely would add value in overall assessment by measuring the impact of the disease as well as treatment.

\section{CSF Cytology/Flow Cytometry}

CSF cytology is usually a qualitative analysis whereby results are reported as negative, atypical, suspicious, or positive. ${ }^{15-18}$ The majority of RCT have utilized a binary outcome measure, that is, either positive or negative such that an atypical report is considered negative and likewise a suspicious determination is considered positive. The RANO LM working group endorses this methodology. Furthermore, the committee is cognizant that quantitative CSF cytology might theoretically be a more accurate descriptor of treatment response but is rarely performed in practice and may not be valid for various reasons, including the vagaries of CSF flow dynamics. Therefore, at this time, response based on CSF cytology is considered when CSF converts from positive to negative (a complete CSF response) and in which a confirmatory determination is made from all sites (lumbar or ventricular) previously shown to be positive. In instances where a ventricular access device has been placed for intra-CSF chemotherapy administration, both sites (lumbar and ventricular) should be sampled to confirm a response. In addition, the duration of response is important. The working group believes a cytological response would be declared in instances where 
Table 1 Neurological examination (adapted from RANO Neurological Assessment group)

\begin{tabular}{|c|c|c|c|c|c|}
\hline \multirow[t]{2}{*}{ Domain } & \multicolumn{4}{|c|}{ Level of Function Score } & \multirow[t]{2}{*}{ Key Considerations } \\
\hline & 0 & 1 & 2 & 3 & \\
\hline Gait & Normal & $\begin{array}{l}\text { Abnormal but } \\
\text { walks without } \\
\text { assistance }\end{array}$ & $\begin{array}{l}\text { Abnormal and } \\
\text { requires assistance } \\
\text { (companion, cane, } \\
\text { walker, etc.) }\end{array}$ & Unable to walk & $\begin{array}{l}\text { 1. Walking is ideally assessed by at least } \\
10 \text { steps. }\end{array}$ \\
\hline Strength & Normal & $\begin{array}{l}\text { Movement present } \\
\text { but decreased } \\
\text { against resistance }\end{array}$ & $\begin{array}{l}\text { Movement present } \\
\text { but none against } \\
\text { resistance }\end{array}$ & No movement & $\begin{array}{l}\text { 1. Each limb should be tested separately. } \\
\text { 2. Recommend assess proximal (above } \\
\text { knee or elbow) and distal (below knee } \\
\text { or elbow) major muscle groups. } \\
\text { 3. Score should reflect worst perform- } \\
\text { ing area. } \\
\text { 4. Patients with preexisting level } 3 \text { func- } \\
\text { tion in one major muscle group/limb } \\
\text { at baseline can be scored based on } \\
\text { assessment of other major muscle } \\
\text { groups/limb. }\end{array}$ \\
\hline Sensation & Normal & $\begin{array}{l}\text { Decreased but } \\
\text { aware of sensory } \\
\text { modality }\end{array}$ & $\begin{array}{l}\text { Unaware of sensory } \\
\text { modality }\end{array}$ & -------- & $\begin{array}{l}\text { 1. Recommend evaluating major body } \\
\text { areas separately (face, limbs, and } \\
\text { trunk). } \\
\text { 2. Score should reflect worst perform- } \\
\text { ing area. } \\
\text { 3. Sensory modality includes but is not } \\
\text { limited to light touch, pinprick, tem- } \\
\text { perature, and proprioception. } \\
\text { 4. Patients with preexisting level } 2 \\
\text { function in one major body area at } \\
\text { baseline can be scored based on } \\
\text { assessment of other major body } \\
\text { areas. }\end{array}$ \\
\hline Vision & Normal & $\begin{array}{l}\text { Partial monocular } \\
\text { visual loss }\end{array}$ & $\begin{array}{l}\text { Complete monocular } \\
\text { visual loss }\end{array}$ & $\begin{array}{l}\text { Bilateral visual } \\
\text { loss }\end{array}$ & $\begin{array}{l}\text { 1. Patients who require corrective lenses } \\
\text { should be evaluated while wearing } \\
\text { corrective lenses. } \\
\text { 2. Each eye should be evaluated, and } \\
\text { score should reflect worst performing } \\
\text { eye. }\end{array}$ \\
\hline $\begin{array}{l}\text { Eye } \\
\text { movements }\end{array}$ & Normal & $\begin{array}{l}\text { Abnormality noted } \\
\text { in } 1 \text { direction of } \\
\text { gaze }\end{array}$ & $\begin{array}{l}\text { Abnormality noted } \\
\text { in more than } 1 \text { gaze } \\
\text { direction, but not all }\end{array}$ & $\begin{array}{l}\text { Unable to move } \\
\text { the eye in any } \\
\text { gaze direction }\end{array}$ & $\begin{array}{l}\text { 1. Test eye movements for each eye } \\
\text { individually. } \\
\text { 2. The score will reflect the worst per- } \\
\text { forming eye (ie, the highest score). }\end{array}$ \\
\hline $\begin{array}{l}\text { Facial } \\
\text { strength }\end{array}$ & Normal & $\begin{array}{l}\text { Mild facial weakness } \\
\text { (nasolabial } \\
\text { fold flattening, }\end{array}$ & $\begin{array}{l}\text { Severe facial weak- } \\
\text { ness (severe nasola- } \\
\text { bial fold flattening, }\end{array}$ & $\begin{array}{l}\text { Bilateral facial } \\
\text { weakness }\end{array}$ & $\begin{array}{l}1 \text { Weakness includes nasolabial fold } \\
\text { flattening, asymmetric smile, and dif- } \\
\text { ficulty elevating eyebrow. }\end{array}$ \\
\hline
\end{tabular}
asymmetric smile, asymmetric smile with decreased forehead limited or no movecontraction, or ment of face, incompartial eye closure) plete eye closure, or labial incompetence

$\begin{array}{lllll}\text { Hearing Normal } & \text { Impaired but } & \begin{array}{l}\text { Absent unilateral } \\ \text { residual serviceable } \\ \text { hearing }\end{array} & \begin{array}{l}\text { Bilateral hearing } \\ \text { hearing }\end{array} & \begin{array}{l}\text { 1. Each ear should be evaluated and } \\ \text { loss } \\ \text { ing ear. }\end{array} \\ \text { Swallowing Normald reflect worst perform- }\end{array}$
in diet formulation, tion by bedside testing not aspirating by bedside testing

\begin{tabular}{lll}
$\begin{array}{l}\text { Level of con- Normal } \\
\text { sciousness }\end{array}$ & $\begin{array}{l}\text { Drowsy (easily } \\
\text { arousable \& } \\
\text { responsive) }\end{array}$ & $\begin{array}{l}\text { Somnolent (difficult } \\
\text { to arouse \& poorly } \\
\text { responsive) }\end{array}$ \\
Behavior Normal & $\begin{array}{l}\text { Mild/moderate } \\
\text { alteration }\end{array}$ & Severe alteration \\
\hline
\end{tabular}

Coma (unarousable \& unresponsive) alteration

Other Normal Occasional or mild $\begin{aligned} & \begin{array}{l}\text { Persistent, moderate } \\ \text { to severe }\end{array} \\ & \text { to }\end{aligned}$
1. Alteration includes but is not lim- ited to apathy, disinhibition, and confusion.

3. Consider subclinical seizures for significant alteration. 
Table 2. MRI parameters in leptomeningeal disease

MRI prerequisites

1.5T and 3T MR scanners only

Use of same MRI at baseline and follow-up

MRI to be performed prior to lumbar puncture

Recommended MRI sequences

Brain

Volumetric 3DT1 (magnetization-prepared rapid acquisition with gradient echo [MPRAGE] or spoiled gradient [SPGR]) postcontrast image with isotropic 1-mm voxels to permit reformatting in 3 planes (axial, coronal, and sagittal)

Reformatted slice thickness $3 \mathrm{~mm}$ to obtain good signal to noise ration and manageable number of slices for full brain coverage

IV contrast dose $=0.1 \mathrm{mmol} / \mathrm{kg}$ of gadolinium-based agent.

Spine

Volumetric 3DT1 (MPRAGE or SPGR) postcontrast image in sagittal plane with isotropic $1 \mathrm{~mm}$ voxels to permit reformatting in 3 planes (axial, coronal, and sagittal) with a $2-3 \mathrm{~mm}$ reformatted slice thickness without gap.

the CSF is cleared of identifiable tumor cells from all sites of identified disease and maintains that status for 4 weeks, a time period felt to be clinically relevant. Nonetheless, the working group recognizes the limitations of cytological response, as the sensitivity of CSF cytology is poor and the potential of making a declaration of "response" even though tumor cells are still present in CSF but not found (ie, a false negative) may be as high as $50 \% .{ }^{15}$ Importantly, results of CSF cytology are dependent upon a number of factors, including (i) whether sufficient volume (a minimum of $10 \mathrm{~mL}$ ) is obtained at time of acquisition, (ii) a site is selected as close to symptomatic or radiographically proven disease as possible to obtain CSF (for example, patients with primarily intracranial LM more often have positive CSF cytology from an intracranial site compared with lumbar CSF sampling), and (iii) rapid processing by pathology occurs after obtaining CSF for analysis. ${ }^{16,19}$ Designation as progressive or refractory disease based upon CSF assessment does not require a confirmatory CSF analysis following a treatment course which fails to show a complete response. Progressive disease is defined by either conversion of negative to positive CSF cytology or failure to convert positive cytology to negative following induction (duration may vary according to treatment and trial design) [refractory disease] (Table 3). A practical issue with the declaration of refractory disease in a patient with persistently positive CSF cytology after induction therapy is seen in the instance wherein patients are otherwise clinically and radiographically stable or improved. The working group was unable to achieve a consensus in this clinical scenario notwithstanding evidence from RCT that suggests survival in patients with persistently positive CSF cytology following induction therapy with intra-CSF chemotherapy is abbreviated relative to patients in whom CSF conversion is seen. However, prior studies have not defined response parameters for clinical or radiological disease progression and as such, interpreting the meaning of positive CSF cytology in an otherwise stable patient is difficult. Currently 2 clinical trials in France of women with breast cancer and LM have elected not to consider CSF cytology as a primary response criterion and when completed will clarify the utility of CSF cytology in this solid tumor-related LM.

CSF FC in contrast is a quantitative analysis that utilizes a binary outcome (ie, positive or negative, like CSF cytology). ${ }^{20-30}$ This method has been evaluated mainly for hematologic LM and is used as an additional (or replacement) method to cytology. ${ }^{20}$ An advantage of FC is that it relies on automation, thus allowing an objective determination of CSF tumor burden as contrasted with the subjective morphology interpretation by CSF cytology. ${ }^{21}$ The sensitivity of FC permits detection of very low CSF disease burden, as low as $0.1 \%$ of the total CSF cell count. $^{24}$ In patients with lymphoma, positive FC even in the presence of negative CSF cytology has been associated with increased risk of CNS relapse, suggesting that even a low burden of disease is clinically relevant. ${ }^{22,25,26}$ False positive results have been reported in patients with inflammatory diseases and without known hematologic malignancy. ${ }^{27}$ Therefore, in patients without known hematologic malignancy, FC results should be interpreted with caution. ${ }^{18,22}$ A limitation of CSF FC is that cancer cells deteriorate rapidly after removal, especially when centrifuged many times. ${ }^{23}$ However, with the use of a stabilizing medium, FC may be reliably performed up to 18 hours after collection of the CSF ${ }^{29}$ Nevertheless, this technique requires standardization, with special attention given to speed of processing, adequate use of centrifugation, and buffer use to permit cell viability as well as optimal use of markers. ${ }^{23,30}$ Response to treatment would be assessed similar to that of CSF cytology. Despite the greater sensitivity of FC, very infrequently FC remains negative in a patient with positive cytology; therefore, the two techniques should be used in parallel in patients with hematologic malignancies. ${ }^{20,25}$ CSF FC as used to assess LM in patients with hematologic cancers, if persistently positive, constitutes refractory disease irrespective of neurological or radiological determination dissimilar to the definition of progressive disease when utilizing CSF cytology (Table 3). 
Table 3. Scorecard for radiographic assessment in leptomeningeal metastases

\begin{tabular}{|c|c|c|c|}
\hline MRI Findings & $\begin{array}{l}\text { Present (1) or Absent (0) or } \\
\text { Non-evaluable (NE) }\end{array}$ & $\begin{array}{l}\text { Dimensions Of Measurable Nodules } \\
\text { Defined as } \\
>5 \times 10 \mathrm{~mm} \text { (orthogonal diameters) }\end{array}$ & $\begin{array}{l}\text { Change from } \\
\text { Previous MRI } \\
(-3 \text { to }+3)\end{array}$ \\
\hline \multicolumn{4}{|l|}{ BRAIN } \\
\hline \multicolumn{4}{|l|}{$\begin{array}{l}\text { Nodules (subarachnoid or } \\
\text { ventricular) }\end{array}$} \\
\hline \multicolumn{4}{|l|}{ Leptomeningeal enhancement* } \\
\hline \multicolumn{4}{|l|}{ Cranial nerve enhancement } \\
\hline \multicolumn{4}{|l|}{ Hydrocephalus^^} \\
\hline \multicolumn{4}{|l|}{ Parenchymal (brain metastases)^ $^{\wedge}$} \\
\hline \multicolumn{4}{|l|}{ SPINE } \\
\hline \multicolumn{4}{|l|}{ Nodules (subarachnoid) } \\
\hline \multicolumn{4}{|l|}{ Leptomeningeal enhancement } \\
\hline \multicolumn{4}{|l|}{ Nerve root enhancement } \\
\hline \multicolumn{4}{|l|}{$\begin{array}{l}\text { Parenchymal(intramedullary } \\
\text { metastases)^ }\end{array}$} \\
\hline \multicolumn{4}{|l|}{ Epidural metastasis ${ }^{\wedge}$} \\
\hline \multicolumn{4}{|l|}{ TOTAL SCORE } \\
\hline \multicolumn{4}{|c|}{$\begin{array}{l}\text { Legend: } \\
\text { *Leptomeningeal enhancement may include pia, cerebellar folia, ventricular ependyma or cerebral sulci. } \\
\text { ^Both hydrocephalus and parenchymal metastases, either brain or spine, are noted as present or absent but not used for LM response determina- } \\
\text { tion. } \\
\text { Column 2: scored as } 1 \text { (present) or } 0 \text { - (absent) or non-evaluable (NE). A maximum of } 5 \text { radiographic target lesions are selected from baseline imaging } \\
\text { to score on follow-up. } \\
\text { Column 3: scores each measurable lesion (at least } 5 \times 10 \mathrm{~mm} \text { ) excluding parenchymal as } 1 \text { (present with maximum orthogonal diameters) or } 0 \text { (ab- } \\
\text { sent). } \\
\text { Column 4: change from baseline or prior image scored as same }(0) \text {, probable improvement }(+1) \text {, definite improvement ( }+2 \text { ), no evidence of disease } \\
\text { (+3) or probable worsening (-1), definite worsening }(-2) \text {, new site }(s) \text { of disease }(-3) \text {. Measurable nodules defined as } \geq 5 \times 10 \mathrm{~mm} \text { are scored as same } \\
\text { (0), resolved (no evidence of disease, complete response), definitely better ( }+2 ; \text { partial response) [decrease by }>50 \% \text { in the summed product of } \\
\text { orthogonal diameters], definite worsening }(-2 \text {; progressive disease) [increase by }>25 \% \text { in the summed product of orthogonal diameters]. A compos- } \\
\text { ite score (total score) is calculated and compared with the baseline total score. A } 25 \% \text { worsening in the current score relative to baseline defines } \\
\text { radiographic progressive disease. A } 50 \% \text { improvement in the current score defines a radiographic partial response. Resolution of all baseline radio- } \\
\text { graphic abnormalities defines a complete response. All other situations define stable disease. }\end{array}$} \\
\hline
\end{tabular}

CSF assessment (CSF cytology in all cancers and combined CSF cytology and FC in hematologic malignancies) is suggested at baseline and repeated with each cycle of LM-directed therapy (once weekly or twice monthly during induction, monthly or bimonthly during maintenance therapy). The addition of CSF protein, glucose, and cell count is not recommended in assessing response to treatment in clinical trials, as these adjunctive measures rarely reflect disease response but may be useful in other clinical contexts such as treatment-related toxicity or CSF cytology-negative LM. In the future, advancement in methodologies for the identification of CSF circulating tumor cells-for example, utilizing rare cell capture technology or CellSearch - will potentially be more sensitive, and if validated, such methods might warrant revisions in the current recommendations. ${ }^{31-35}$ Similarly, identification of new soluble CSF biomarkers might, if validated, alter current response definitions. ${ }^{36-41}$ The use of novel biomarkers such as tumor antigens, signaling pathway molecules involved in extravasation, adhesion, migration, angiogenesis, and chemokines are currently being evaluated as to a role for improved detection and treatment of LM, but none of these assays have been validated. ${ }^{36-41}$

\section{Neuroimaging Assessment}

The most challenging element of response assessment in LM is the neuroimaging evaluation. The question of whether MRI assessment can replace CSF analysis has never been addressed, primarily as (i) there are no criteria for adjudicating response by MRI in LM disease, (ii) MRI is underused in a standardized manner in RCT of LM disease, and (iii) perhaps most importantly, normal MRI assessment in patients with LM disease is not infrequent. MRI assessment of the neuraxis is useful only when positive and as such in patients with negative MRI, alternative methods of response are required.

MRI abnormalities of LM include enhancement of the leptomeninges of the brain or spinal cord identified as 
Table 4. Response determination in leptomeningeal metastases

\begin{tabular}{|c|c|c|c|c|c|c|}
\hline \multirow[t]{2}{*}{ Assessment } & \multirow[t]{2}{*}{ Response } & \multicolumn{4}{|c|}{ Progressive or refractory disease } & \multirow[t]{2}{*}{ Stable Disease } \\
\hline & & $\begin{array}{l}\text { Neurological } \\
\text { Examination } \\
\text { Defined } \\
\text { Progression }\end{array}$ & $\begin{array}{l}\text { CSF Defined } \\
\text { Disease } \\
\text { Progression }\end{array}$ & $\begin{array}{l}\text { Radiologic } \\
\text { Defined Disease } \\
\text { Progression }\end{array}$ & Symptoms^ & \\
\hline $\begin{array}{l}\text { Neurological } \\
\text { Exam }\end{array}$ & Improved & Worse & Stable & Stable & Stable & Stable \\
\hline $\begin{array}{l}\text { CSF cytology } \\
\text { (all cancers) }\end{array}$ & Negative & Negative & $\begin{array}{l}\text { Positive (lack } \\
\text { consensus) }\end{array}$ & Negative & Negative & $\begin{array}{l}\text { Negative or positive } \\
\text { (solid tumors only) }\end{array}$ \\
\hline $\begin{array}{l}\text { CSF flow } \\
\text { cytometry } \\
\text { (in hematologic } \\
\text { cancers only) }\end{array}$ & Negative & Negative & $\begin{array}{l}\text { Positive } \\
\text { (lack consensus) }\end{array}$ & Negative & Negative & Negative or positive \\
\hline $\begin{array}{l}\text { CNS } \\
\text { imaging }\end{array}$ & $\begin{array}{l}\text { Definite } \\
\text { improvement }\end{array}$ & Stable & Stable & $\begin{array}{l}\text { Definite } \\
\text { worsening }\end{array}$ & Stable & $\begin{array}{l}\text { Stable or equivocally } \\
\text { worsening or improved }\end{array}$ \\
\hline $\begin{array}{l}\text { Steroid dose } \\
\text { (in hematologic } \\
\text { cancers only) }\end{array}$ & $\begin{array}{l}\text { None or } \\
\text { decreased }\end{array}$ & $\begin{array}{l}\text { Stable or } \\
\text { increased }\end{array}$ & $\begin{array}{l}\text { Stable or } \\
\text { increased }\end{array}$ & $\begin{array}{l}\text { Stable or } \\
\text { increased }\end{array}$ & Stable & Stable or decreased \\
\hline $\begin{array}{l}\text { Symptom } \\
\text { assessment }\end{array}$ & Improved & Worse or stable & Worse or stable & Worse or stable & Worse & Stable \\
\hline $\begin{array}{l}\text { Legend: } \\
\text { CSF cytology negat } \\
\text { CSF cytology positi } \\
\text { Stable Defined as s } \\
\text { Symptoms }{ }^{\wedge} \text { Stable; } \\
\text { Worse; }-2 \text { to }-3 \text { in } s \\
\text { Improved; }+2 \text { to }+3\end{array}$ & $\begin{array}{l}\text { tive Defined as ei } \\
\text { ve Defined as tru } \\
\text { table or indeterm } \\
\text { no change (-1 to } \\
\text { symptom inventor } \\
\text { in symptom inver }\end{array}$ & $\begin{array}{l}\text { ther true negative } \\
\text { e positive or suspici } \\
\text { ninate } \\
+1 \text { in symptom inve } \\
\text { ry } \\
\text { ttory }\end{array}$ & $\begin{array}{l}\text { typical } \\
\text { Is } \\
\text { ory }\end{array}$ & & & \\
\hline
\end{tabular}

enhancement of the cranial nerves and spinal nerve roots, brain surface, cerebellar foliae, and within cerebral sulci. ${ }^{42-49}$ Pathological enhancement may be nodular, linear, or curvilinear as well as focal or diffuse. Because radiographic features typical of LM are generally small in volume and complex in geometry, current MRI technology does not permit quantitative assessment. ${ }^{31-33}$ Nodules in the subarachnoid space or ventricles are often difficult to measure because they are small (often $<5 \mathrm{~mm}$ ), adjoined by linear enhancement, and subject to inter-MRI variability due to slice positioning and contrast conspicuity. The working group recommends that nodular disease that is $\geq 5 \times 10 \mathrm{~mm}$ in orthogonal diameters be defined as measurable and be serially assessed in follow-up imaging. Synchronous or metachronous presence of parenchymal brain or spine metastases should be considered separately from response definitions for LM and would be adjudicated independently as previously described. ${ }^{50}$

The working group recommends contrast MRI of brain and entire spine at baseline and at prespecified times thereafter, such as following completion of induction therapy. Other neuroimaging modalities (MR spectroscopy, MR perfusion, and PET) do not currently have a defined role in the assessment of LM. Radioisotope cisternography, also referred to as CSF flow studies, is recommended only in patients considered for intra-CSF therapy, as disruption of CSF movement impacts intra-CSF drug delivery. ${ }^{51-55}$

Suggested imaging requirements for MRI are given in Table 2. Interpretation of MRI emphasizes areas of pathological gadolinium enhancement consistent with LM.
Presence or absence of hydrocephalus should be noted and contribute to response assessment. However, changes in hydrocephalus volume are not part of the proposed system for assessment of LM response. It is proposed that 6 regions (outlined in Table 3 ) of the CNS be assessed for pathological contrast enhancement on MRI consistent with LM, with findings for each region documented at baseline as present (abnormality present), absent (no abnormality; normal), or non-evaluable (NE). In follow-up, features in these regions (or new regions of involvement) should be assessed as completely resolved $(+3)$, definitely improved $(+2)$, possibly improved $(+1)$, unchanged $(0)$, possibly worse $(-1)$, definitely worse $(-2)$, or new site of disease (-3), as perTable 3. A scheme for combining these assessments to determine response to treatment is given in Tables 3 and 4. Assessment should emphasize changes in size and extent but not in intensity of enhancement. Subarachnoid or ventricular nodules with nonmeasurable dimensions should be noted and considered in assessing change as with enhancement. Nodules that are measurable are defined as definitely worse if $>25 \%$ of the baseline sum of the product of their orthogonal diameters. Similarly, if the summed product of orthogonal diameters of the tumor nodules decreases $>50 \%$, then response would be graded as definitely improved (ie, partial response). Nodules that disappear on treatment would be graded as a complete response for this defined target lesion only. All other parameters of measurable nodules would be rated as stable. Overall radiographic response is determined by the composite score for both measurable and nonmeasurable 
lesions. Up to 5 target radiographic lesions (either measurable or nonmeasurable) are selected at baseline and followed serially to permit response assessment (Table 3). Radiographic response may reflect treatment with either chemotherapy (systemic or intra-CSF) or involved-field radiotherapy. Fluid attenuated inversion recovery (FLAIR) and T2 abnormalities without enhancement are not assessable as features of LM and may result in false positive interpretation. Changes in parenchymal brain or spine metastases should be noted but are not considered in the radiological assessment of $L M$.

Several caveats regarding this proposed radiographic assessment of LM are to be noted. The conspicuity of enhancing features may vary with gadolinium formulation and dose, rapidity of infusion, and elapsed time between infusion and image acquisition. Image raters are encouraged to note the prominence of enhancement of normal enhancing features (dura, falx, choroid plexus, vessels, and leptomeninges) and account for these normal features when assessing change on successive scans. Raters should be especially circumspect about interpreting response of leptomeningeal contrast enhancement without nodularity. Care should be taken to avoid considering enhancement due to LM which results from intra-CSF treatment, postsurgical enhancement of dura/arachnoid, skull metastases, intracranial hypotension (especially after a lumbar puncture or placement of a ventriculoperitoneal shunt), blood vessels, etc. For nodules that are not measurable as defined above, raters are advised to be conservative about interpreting possible changes that may be due to different slice spacing.

Clinical, MRI, and CSF assessments should ideally be performed at the same timepoints, but with MRI preceding lumbar puncture. MRI should be avoided shortly after lumbar puncture to minimize false positive meningeal enhancement. ${ }^{48,56}$

The recommendations for neuroimaging assessment of LM have not been validated and should be regarded as a work in progress. Experience with this proposed strategy and advances in technology-for example, postcontrast T2-FLAIR MRI-are likely to refine and improve neuroimaging assessment of LM in the future. ${ }^{57-59}$

\section{Conclusions}

Response evaluation in LM is a challenging subject in neuro-oncology in that there exists little to no consensus. The RANO LM working group proposes a composite response assessment wherein evaluation of the neurological examination is performed using a newly proposed standardized instrument, CSF cytology/FC evaluation, along with a composite score of MRI of the CNS, which also is a newly proposed instrument. These 3 elements (neurological examination, presence or absence of CSF circulating tumor cells, and neuraxis imaging) are used together and at each response assessment. While the current proposed response criteria for LM does not account for all aspects of this metastatic complication (for example, response of brain metastases or systemic cancer), it does provide a framework for use in clinical trials. The novel response instruments proposed herein require validation and likely modification over time to account for changes in CSF and CNS imaging diagnostics as they pertain to LM. Importantly in the current proposal, progressive disease is defined in 2 specific contexts: worsening neurological examination due to LM (sufficient in isolation), persistently positive CSF cytology or FC (insufficient in isolation), or worsening neuroradiographic assessment (sufficient in isolation) (Table 4). The latter category of radiological progressive LM (Table 2) is like the neurological examination: a composite score and a newly proposed instrument that will require validation and likely modification with use and new methodology. The inclusion of an assessment by a symptom burden instrument as shown in Table 3 is proposed as having clinical relevance in that elements of LM that are defined only by symptoms (headache, seizures) are not included by standard response tools.

\section{Acknowledgment}

We would like to express our appreciation for the expert administrative assistance provided by Alisa Clein.

Authors report no conflicts of interest to declare. 
8. Groves MD, Glantz MJ, Chamberlain MC, et al. A multicenter phase II trial of intrathecal topotecan in patients with meningeal malignancies. Neuro Oncol. 2008;10(2):208-215.

9. Gajjar A, Fouladi M, Walter AW, et al. Comparison of lumbar and shunt cerebrospinal fluid specimens for cytologic detection of leptomeningeal disease in pediatric patients with brain tumors. J Clin Oncol. 1999;17(6):1825-1828.

10. Armstrong TS, Wefel JS, Wang M, et al. Net clinical benefit analysis of radiation therapy oncology group 0525: a phase III trial comparing conventional adjuvant temozolomide with dose-intensive temozolomide in patients with newly diagnosed glioblastoma. J Clin Oncol. 2013;31(32):4076-4084.

11. Brandberg $Y$, Johansson $H$, Aamdal S, et al. Role functioning before start of adjuvant treatment was an independent prognostic factor for survival and time to failure. A report from the Nordic adjuvant interferon trial for patients with high-risk melanoma. Acta Oncol. 2013;52(6):1086-1093.

12. Chamberlain MC. Neoplastic meningitis: deciding who to treat. Expert Rev Neurotherap. 2004;4(4):89-96.

13. Shapiro WR, Young DF, Mehta BM. Methotrexate: distribution in cerebrospinal fluid after intravenous, ventricular and lumbar injections. $N$ Engl J Med. 1975;293(4):161-166.

14. Siegal T. Leptomeningeal metastases: rationale for systemic chemotherapy or what is the role of intra-CSF-chemotherapy? J Neuro Oncol. 1998;38(2-3):151-157.

15. Jung $H$, Sinnarajah A, Enns B, et al. Managing brain metastases patients with and without radiotherapy: initial lessons from a team-based consult service through a multidisciplinary integrated palliative oncology clinic. Support Care Cancer. 2013;21(12):3379-3386.

16. Quinten C, Martinelli F, Coens C, et al. Patient Reported Outcomes and Behavioral Evidence (PROBE) and the European Organization for Research and Treatment of Cancer (EORTC) Clinical Groups. A global analysis of multitrial data investigating quality of life and symptoms as prognostic factors for survival in different tumor sites. Cancer. 2014;120(2):302-311.

17. Glass JP, Melamed M, Chernik NL, et al. Malignant cells in cerebrospinal fluid (CSF): the meaning of a positive CSF cytology. Neurology. 1979;29(10):1369-1375.

18. Glantz MJ, Cole BF, Glantz LK, et al. Cerebrospinal fluid cytology in patients with cancer: minimizing false-negative results. Cancer. 1998:82(4):733-739.

19. Chamberlain MC, Glantz M, Groves MD, et al. Diagnostic tools for neoplastic meningitis: detecting disease, identifying patient risk, and determining benefit of treatment. Semin Oncol. 2009;36(suppl):S35-45.

20. Strik H, Luthe H, Nagel I, et al. Automated cerebrospinal fluid cytology: limitations and reasonable applications. Anal Quant Cytol Histol. 2005;27(3):167-173.

21. Rogers LR, Duchesneau PM, Nunez $C$, et al. Comparison of cisternal and lumbar CSF examination in leptomeningeal metastasis. Neurology. 1992;42(6):1239-1241.

22. Nuckel H, Novotny J, Noppeney R, et al. Detection of malignant haematopoietic cells in the cerebrospinal fluid by conventional cytology and flow cytometry. Clin Lab Haem. 2006;28(1):22-29.

23. Aune MW, Becker JL, Brugnara C, et al. Automated flow cytometric analysis of blood cells in cerebrospinal fluid: analytic performance. Am J Clin Pathol. 2004;121(5):690-700.

24. Sancho JM, Orfao A, Quijano S, et al. Clinical significance of occult cerebrospinal fluid involvement assessed by flow cytometry in non-Hodgkin's lymphoma patients at high risk of central nervous system disease in the rituximab era. Eur J Haematol. 2010;85(4):321-328.

25. Dux R, Kindler-Röhrborn A, Annas M, et al. A standardized protocol for flow cytometric analysis of cells isolated from cerebrospinal fluid. $J$ Neurol Sci. 1994;121(1):74-78

26. Hedge U, Fille A, Little RF, et al. High incidence of occult leptomenigeal disease detected by flow cytometry in newly diagnosed aggresive B-cell lymphomas at risk for central nervous system involvement: the role of flow cytometry versus cytology. Blood. 2005;105(2):496-502.

27. Bromberg JE, Breems DA, Kraan J, et al. CSF flow cytometry greatly improves diagnostic accuracy in CNS hematologic malignancies. Neurology. 2007; 68(20):1674-1679.

28. Benevolo G, Stacchini A, Spina M, et al. Final results of a multicenter trial addressing role of CSF flow cytometric analysis in NHL patients at high risk for CNS dissemination. Blood. 2012; 120(16):3222-3228.

29. Nowakowski GS, Call TG, Morice WG, et al. Clinical significance of monoclonal B cells in cerebrospinal fluid. Cytometry B Clin Cytom. 2005;63(1):23-27.

30. de Graaf MT, de Jongste AH, Kraan J, et al. Flow cytometric characterization of cerebrospinal fluid cells. Cytometry B Clin Cytom. 2011;80(5):271-281.

31. Quijano S, Lopez A, Manuel SJ, et al. Identification of leptomeningeal disease in aggressive B-cell non-Hodgkin's lymphoma: improved sensitivity of flow cytometry. J Clin Oncol. 2009; 27(9):1462-1469.

32. Kraan J, Gratama JW, Haioun C, et al. Flow cytometric immunophenotyping of cerebrospinal fluid. Curr Protoc Cytom. 2008;Chapter 6: Unit6.25.

33. Nayak L, Fleisher M, Gonzalez-Espinosa R, et al. Rare cell capture technology for the diagnosis of leptomeningeal metastaseis in slide tumors. Neurology. 2013;80(17):1598-1605.

34. Patel AS, Allen JE, Dicker DT, et al. Identification and enumeration of circulating tumor cells in the cerebrospinal fluid of breast cancer patients with central nervous system metastases. Oncotarget. 2011;2(10):752-760.

35. Le Rhun E, Massin F, Tu Q, et al. Development of a new method for identification and quantification in cerebrospinal fluid of malignant cells from breast carcinoma leptomeningeal metastasis. BMC Clin Pathol. 2012;12(1):21.

36. Le Rhun E, Tu Q, De Carvalho Bittencourt M, et al. Detection and quantification of CSF malignant cells by the CellSearch technology in patients with melanoma leptomeningeal metastasis. Med Oncol. 2013;30(2):538.

37. Subira D, Simo M, Illan J, et al. Diagnostic and prognostic significance of flow cytometry immunophenophenotyping in patients with leptomeningeal carcinomatosis. Clin Exp Metastasis. 2015;32(4):383-391.

38. Chamberlain MC. Cytologically negative carcinomatous meningitis: usefulness of CSF biochemical markers. Neurology. 1998;50(4):1173-1175.

39. Groves M, Hess KR, Puduvalli VK, et al. Biomarkers of disease: cerebrospinal fluid vascular endothelial growth factor (VEGF) and stromal cell derived factor (SDF)-1 levels in patients with neoplastic meningitis (NM) due to breast cancer, lung cancer and melanoma. J Neurooncol. 2009;94(2):229-234.

40. Corsini E, Bernardi G, Gaviani P, et al. Intrathecal synthesis of tumor markers is a highly sensitive test in the diagnosis of leptomeningeal metastasis from solid cancers. Clin Chem Lab Med. 2009;47(7):874-879.

41. Römpp A, Dekker L, Taban I, et al. Identification of leptomeningeal metastasis-related proteins in cerebro-spinal fluid of patients with breast cancer by a combination of MALDI-TOF, MALDI-FTICR and nanoLC-FTICR MS. Proteomics. 2007;7(3):474-481.

42. Weston CL, Glantz MJ, Connor JR. Detection of cancer cells in the cerebrospinal fluid: current methods and future directions. Fluids Barriers CNS. 2011;8(1):14.

43. Walbert T, Groves MD. Known and emerging biomarkers of leptomeningeal metastasis and its response to treatment. Future Oncol. 2010;6(2):287-297

44. Chamberlain MC. Comparative spine imaging in leptomeningeal metastases. J Neuro Oncol. 1995;23(3):233-238.

45. Freilich RJ, Krol G, DeAngelis LM. Neuroimaging and cerebrospinal fluid cytology in the diagnosis of leptomeningeal metastasis. Ann Neurol. 1995;38(1):51-57.

46. Chamberlain MC, Kormanik PA. Prognostic significance of coexistent bulky metastatic central nervous system disease in patients with leptomeningeal metastases. Arch Neurol. 1997;54(11):1364-1368. 
47. Clarke JL, Perez HR, Jacks LM, et al. Leptomeningeal metastasis in the MRI era. Neurology. 2010;74(8):1449-54.

48. Pauls S, Fischer AC, Brambs $\mathrm{HJ}$, et al. Use of magnetic resonance imaging to detect neoplastic meningitis: limited use in leukemia and Iymphoma but convincing results in solid tumors. Eur $J$ Radiol. 2012;81(5):974-978.

49. Chamberlain MC. Comprehensive neuraxis imaging in leptomeningeal metastasis: a retrospective case series. CNS Oncology. 2013;2(2):121-128.

50. Smirniotopoulos JG, Murphy FM, Rushing EJ, et al. Patterns of contrast enhancement in the brain and meninges. Radiographics. 2007; 27(2):525-551.

51. Singh SK, Leeds NE, Ginsberg LE. MR imaging of leptomeningeal metastases: comparison of three sequences. AJNR Am J Neuroradiol. 2002;23(5):817-821.

52. Lin NU, Wefel JS, Lee EQ, et al. Challenges relating to solid tumor brain metastases in clinical trials, part 2: neurocognitive, neurological, and quality-of-life outcomes: a report from the RANO group. Lancet Oncol. 2013;14(10):e407-416.

53. Grossman SA, Trump CL, Chen DCP, et al. Cerebrospinal fluid flow abnormalities in patients with neoplastic meningitis. Am J Med. 1982;73(5):641-647.

54. Chamberlain MC, Kormanik PA. Prognostic significance of 111 indiumDTPA CSF flow studies in leptomeningeal metastases. Neurology. 1996;46(6):1674-1677.
55. Chamberlain MC. Radioisotope CSF flow studies in leptomeningeal metastases. J Neuro Oncol. 1998;38(2-3):135-140.

56. Chamberlain MC, Kormanik $P$, Jaeckle KA, et al. 111Indiumdiethylenetriamine pentaacetic acid CSF flow studies predict distribution of intrathecally administered chemotherapy and outcome in patients with leptomeningeal metastases. Neurology. 1999;52(1):216-217.

57. Mason WP, Yeh SD, DeAngelis LM. ${ }^{111}$ Indium-diethylenetriamine pentaacetic acid cerebrospinal fluid flow studies predict distribution of intrathecally administered chemotherapy and outcome in patients with leptomeningeal metastases. Neurology. 1998;50(2):438-444.

58. Mittl RL, Jr, Yousem DM. Frequency of unexplained meningeal enhancement in the brain after lumbar puncture. Am J Neuroradiol. 1994;15(4):633-8.

59. Mathews VP, Caldemeyer KS, Lowe MJ, et al. Brain: gadoliniumenhanced fast fluid attenuated inversion recovery MR imaging. Radiology. 1999;211(1):257-263.

60. Mamourian AC, Hoopes PJ, Lewis LD. Visualization of intravenously administered contrast material in the CSF on fluid-attenuated inversion recovery MR images: an in vitro and animal model investigation. AJNR Am J Neuroradiol. 2000;21(1):105-111.

61. Fukuoka H, Hirai T, Okuda T, et al. Comparison of the added value of contrast enhanced 3D fluid-attenuated inversion recovery and magnetization prepared rapid acquisition of gradient echosequences in relation to conventional postcontrast TW-weighted images for the evaluation of leptomeningeal diseases at 3T. AJNR Am J Neuroradiol. 2010;31(5):868-873. 